\title{
Analysis of Change Characteristics in Investment Growth of Higher Education in China
}

\author{
Phan Anh Tuan \\ School of Humanities \& Social Science, University of Science and Technology Beijing, Beijing City, China
}

Email address:

fananhtuan@yahoo.com

\section{To cite this article:}

Phan Anh Tuan. Analysis of Change Characteristics in Investment Growth of Higher Education in China. Science Journal of Education. Vol. 4, No. 4, 2016, pp. 129-134. doi: 10.11648/j.sjedu.20160404.12

Received: July 6, 2016; Accepted: July 15, 2016; Published: August 3, 2016

\begin{abstract}
Basing on the statistical data of higher education investment funds during the period of 2005-2013 collected from National Bureau of Statistics of the People's Republic of China and Ministry of Education of the People's Republic of China, this article analyzes changes in the growth of the total investment funds; changes in growth of average investment funds among provinces and cities; changes in growth of investment funds from learners; changes in growth of investment funds and financing from social forces, thereof the change characteristics in investment growth of higher education in China will be identified.
\end{abstract}

Keywords: China, Higher Education, Investment, Change Characteristics

\section{Introduction}

Investment in higher education development is an important task in the training strategy of talents to serve Chinese economic growth. In fact, investment in higher education development in China has significantly contributed to promoting scientific and technical progress, increasing labor productivity, reducing production costs and forming preconditions for Chinese sustainable economic growth as well as improving economic competitiveness internationally. In 2014, the output value of the high-tech sector in Shanghai city accounted for $20 \%$ of the total industrial output value of Shanghai city and the factor of scientific and technological advances also contributed up to $53 \%$ of Shanghai city's economicgrowth rate [10]. Thus, higher education investment is naturally favorable for the scientific and technological advancesand developments, thereby the economic growth is higher.

In recent years, investment funds of higher education in China have been increasing. The training scale has been continuously expanded. Chinese higher education is coming into a stage of education massification and is in the process of universalization. However, there are heterogeneous variations, reasonable nor logical variations appearing during the variation of investment fund growth for Chinese higher education development. This problem naturally has a close relationship with the variation in GDP growth. This article is based on the statistical data of the National Bureau of Statistics of China and the Ministry of Education of China to analyze variations in the correlation between GDP growth and investment growth for Chinese higher education in recent years. Thereby, drawing some basic characteristics as well as pointing out the causes and rationality in investment growth variation for Chinese higher education development.

\section{Features in Chinese GDP Growth Variation During 2005-2013}

Coming into the $21^{\text {st }}$ century, China continues to accelerate the process of economic restructuring leading to higher GDP growth. However, GDP growth during the period of 20052013 is varied by the global financial crisis during the period of 2008-2010 and by a low recovery process of economic growth during the period of 2011-2013 as well as uneven economic developing capacity among economic zones, provinces, urban areas and rural areas.

\subsection{High GDP Growth, Low Inflation}

2005-2013, Chinese GDP growth remains at high rate, but variations in GDP growth over the periods are heterogeneous. 
In particular, Chinese GDP growth is reached high growth in the period of 2005-2007, an undulating increase during the

period of 2008-2010 and growth is tended to go down during the period 2011-2013.

Table 1. Chinese GDP and CPI growth during the period of 2005-2013.

\begin{tabular}{|c|c|c|c|c|c|c|c|c|c|}
\hline Year & 2005 & 2006 & 2007 & 2008 & 2009 & 2010 & 2011 & 2012 & 2013 \\
\hline GDP Scale (billion yuan) & 18589.6 & 21765.7 & 26801.9 & 31675.2 & 34562.9 & 40890.3 & 48412.4 & 53412.3 & 58801.8 \\
\hline GDP growth rate compared to previous year (\%) & 11.3 & 12.7 & 14.2 & 9.6 & 9.2 & 10.6 & 9.5 & 7.7 & 7.7 \\
\hline CPI growth index compared to previous year (\%) & 1.8 & 1.5 & 4.8 & 5.9 & -0.7 & 3.3 & 5.4 & 2.6 & 2.6 \\
\hline
\end{tabular}

Source: National Bureau of Statistics of the People's Republic of China. GDP; per capita GDP and per capita income; CPI 2005-2013. Retrieved from www.stats.gov.cn

2005-2013, Chinese GDP growth is averaging 9.62\%, in which, the high growth in the early period (2005-2007). This is the period when China accelerates the process of economic restructuring, so GDP growth always reaches double digits (11.3\%-14.2\%). The period of 2008-2010, Chinese GDP growth is shown downward compared to the period of 20052007 and undulating growth in wave form due to global financial crisis. Despite the significant impact of the global financial crisis, thanks to reasonable financial and monetary policy, Chinese economic growth in this stage is still at a high rate. The growth rate is $10.6 \%$ in 2010 , Chinese economy surpasses Japanese economy and becomes the second largest economy in the world after the U.S. The period of 2011-2013, Chinese GDP growth weakens and gradually goes down by negative impact from monetary policy and financial policy in the period of 2008-2010. GDP growth in the period of 2011 - 2013 only reaches $7.7 \%$ -
$9.5 \%$.

Economic growth inevitably leads to inflation growth. However, inflation growth index during the period of 2005 2013 is still low, and lower than GDP growth performance (see Table 1). Especially, the period of 2011-2013, index inflation of 2011 is more than $5 \%$, it is maintained below $3 \%$ during the remaining two years. This allows Chinese economy in this stage reaches warm and safe growth condition.

\subsection{Per Capita GDP is Fast Growing, Per Capita GDP Difference Among Provinces, Cities, Is Increasingly Narrow}

High GDP growth leads to fast growth of per capita GDP over the years, the difference in per capita GDP among provinces and cities is into increasingly narrow.

Table 2. Chinese GDP Scale and per capita GPD during the period of 2005-2013.

\begin{tabular}{|c|c|c|c|c|c|c|c|c|c|}
\hline Year & 2005 & 2006 & 2007 & 2008 & 2009 & 2010 & 2011 & 2012 & 2013 \\
\hline GDP Scale (billion yuan) & 18589.6 & 21765.7 & 26801.9 & 31675.2 & 34562.9 & 40890.3 & 48412.4 & 53412.3 & 58801.8 \\
\hline Per capita GDP (yuan) & 14258.9 & 16602.1 & 20337.1 & 23912.0 & 25692.6 & 30567.5 & 36017.6 & 39544.3 & 43320.1 \\
\hline Per capita GDP growth rate compared to previous year (\%) & 10.7 & 12.1 & 13.6 & 9.7 & 8.7 & 10.1 & 9.0 & 7.2 & 7.2 \\
\hline
\end{tabular}

Source: National Bureau of Statistics of the People's Republic of China. GDP; per capita GDP and per capita income; CPI 2005-2013. Retrieved from www.stats.gov.cn

Per capita GDP in 2013 reaches 43320.1 yuan, an increase of 3.03 times compared to 2005 , increased by 1.68 times compared to 2009 . It is divided by provinces and cities, in 2005 provinces and cities with highest per capita GDP are Shanghai (514740.0 yuan), Beijing (45443.7 yuan), Tianjin (35783.2 yuan), Zhejiang (27702.7 yuan), Guangdong (24435.0 yuan). Provinces with lowest per capita GDP are Guangxi (8787.7 yuan), Anhui (8670.0 yuan), Yunnan (7835.0 yuan), Gansu (7476.5 yuan), Guizhou (5052.0 yuan) [7]. Shanghai with the highest difference of per capita GDP and Guizhouwith the lowest difference of per capita GDP by 8.99 times. By 2013, per capita GDP ranking is not much varied. Tianjin (100105.4 yuan), Beijing (94647.9 yuan), Shanghai (90993.0 yuan), Jiangsu (75354.0 yuan), Zhejiang (68804.7 yuan) are the leading provinces in per capita GDP. Anhui (32000.9 yuan), Guangxi (30741.2 yuan), Tibet (26326.0 yuan), Yunnan (25322.0 yuan), Gansu (24538.8 yuan), Guizhou (23151.0 yuan) are the provinces and the cities with the lowest per capita GDP in the ranking of per capita GDP out of 31 provinces and cities [8]. However, Tianjinwith the highest difference of Per capita GDP and
Guizhou with the lowest difference of Per capita GDP fell to 4.32 times in 2013.

\subsection{Growth in Per Capita Income in Urban Areas and Rural Areas Is Clear Difference}

2005-2013, per capita income in urban areas and rural areas is increased over the years. Compared to 2005, per capita income in urban areas is increased by 2.56 times in 2013, per capita income in rural areas is increased by 2.73 times. In the period of 2005-2013, the average annual per capita income in urban areas is increased by 2058 yuan, rural areas is increased by 714.28 yuan. At the same time gap per capita income between urban areas and rural areas is 3 times.

Rating by level of provinces and cities, per capita income between urban areas and rural areas are also not different. Statistical Report of National Bureau of Statistics of the People's Republic of China shows that in 2013, Provinces of Heilongjiang, Tianjin, Beijing, Shanghai and Jilin with the lowest difference of per capita income of urban areas and rural areas (2.03 to 2.32), the highest difference is at provinces of Yunnan (3.78), Gansu (3.71), Shanxi (3.51), 
Guangxi (3.43). It is divided by economic sector, the highest difference per capita income of urban areas and rural areas is the West (3.3), followed by the Central (2.8), the East (2.5).

From the analysis of variation in Chinese GDP growth in the period of 2005-2013, it shows that variation in GDP growth over the period is heterogeneous. Growth in per capita GDP and per capita income has a clear difference between provinces and cities, between urban areas and rural areas and between economic sectors. However, in the terms of overall perspective, Chinese GDP growth in the period during 2005-2013 maintains at safe and high rate, becoming a bright spot in the global economy at this stage.

Table 3. Per capita income of urban areas and rural areas in China, during 2005-2013.

\begin{tabular}{|c|c|c|c|c|c|c|c|c|c|}
\hline Year & 2005 & 2006 & 2007 & 2008 & 2009 & 2010 & 2011 & 2012 & 2013 \\
\hline Per capita income in urban areas (yuan) & 10494 & 11760 & 13786 & 15781 & 17175 & 19019 & 21810 & 24565 & 26955 \\
\hline Per capita income in rural areas (yuan) & 3255 & 3587 & 4140 & 4761 & 5153 & 5919 & 6977 & 7917 & 8896 \\
\hline Different ratio per capita income of urban areas and rural areas & 3.22 & 3.27 & 3.32 & 3.31 & 3.33 & 3.21 & 3.12 & 3.1 & 3.03 \\
\hline
\end{tabular}

Source: National Bureau of Statistics of the People's Republic of China. GDP; per capita GDP and per capita income; CPI 2005-2013. Retrieved from www.stats.gov.cn

\section{Variation Features in Investment Growth for Chinese Higher Education Development During the Period of 2005-2013}

Variations in GDP growth directly impact on variation in investment growth for Chinese higher education development. Through research on variation in investment growth for Chinese higher education development is based on statistical data during the period of 2005-2013, this article discovers some basic variation features as follows:

\subsection{Total Investment Funds Are Continuously Growing, Training Scale Is Constantly Expanding}

Due to the high GDP growth rate and maintaining at safe rate, per capita GDP, population size is increased slowly and in order to achieve the objective of developing talents to serve the process of economic-social development, the total investment funds for higher education development has increased rapidly along with economic growth in recent years.

Table 4. Total investment funds for Chinese higher education from 2005 to 2013.

\begin{tabular}{lllll}
\hline Year & $\mathbf{2 0 0 5}$ & $\mathbf{2 0 0 7}$ & $\mathbf{2 0 0 9}$ & $\mathbf{2 0 1 1}$ \\
\hline Scale of GDP (billion yuan) & 18589.6 & 26801.9 & 34562.9 & 48412.4 \\
GDP growth performance compared to previous year (\%) & 11.3 & 14.2 & 9.2 & 9.5 \\
Total investment funds of higher education (billion yuan) & 265.79 & 376.23 & 478.28 & 702.09 \\
\hline
\end{tabular}

National Bureau of Statistics of the People's Republic of China

From the National Bureau of Statistics' statistical data of higher education budget, it is shown that in 2013, total investment funds for higher education development reaches 774.26 billion yuan, up 2.9 times compared to 2005 . In particular, in 2007 GDP growth reaches $14.2 \%$, total investment for higher education reaches 376.23 billion yuan, up $41.6 \%$ compared to 2005 . After a period influenced by the financial crisis, economic growth tends to downward, but China continues to increase accelerating investment in higher education development. Specifically in 2011, total budget investment reaches 702.09 billion yuan, an increase of $46.7 \%$ over 2009. Increase in investment funds has led to scale of schools, scale of students and higher education enrollment performance increased rapidly over the years.

Table 5. Scale of higher education training and higher education enrollment performance from 2005 to 2013.

\begin{tabular}{|c|c|c|c|c|c|}
\hline Year & 2005 & 2007 & 2009 & 2011 & 2013 \\
\hline Scale of universities (schools) & 2273 & 2321 & 2689 & 2762 & 2788 \\
\hline Number of students studying at the university (ten thousands of students) & 2300 & 2700 & 2979 & 3167 & 3410 \\
\hline Enrollmentgrowth performance compared to previous year $(\%)$ & 21 & 23 & 24.2 & 26.9 & 34.5 \\
\hline
\end{tabular}

Source: Ministry of Education of the People's Republic of China. Statistical Report for Chinese Education Development by 2005-2013. Retrieved from www.moe.gov.cn

2005-2013, scale of schools has increased by 1,2 times, scale of students in universities has increased by 1,48 times for in 9 years. Higher education enrollment performanceis also increased over the years. 2013 per capita GDP reaches 43320.1 yuan, Higher education enrollment performance reaches $34,5 \%$. The enrollment performance is increased at the beginning of the $21^{\text {st }}$ century, marking a historic shifting step in Chinese higher education. Chinese higher education moves to popularization and is in the process of universalization of university education.

Thus, the analysis result shows that the continuous increase in the total investment funds has solved the problem 
of supply and demand in higher education. However, the growth rate of total investment funds of higher education development is higher than the growth rate of training scale. This is easy to realize total investment funds of Chinese higher education development is still missing and is not commensurate with the need to expand the training scale.

\subsection{Growth in Average Expenditure for Higher Education Between Provinces and Cities Has a Clear Difference}

Continuous increase in total investment funds is natural. However, there is a difference in average higher education expenditure between regions, between provinces and cities is inevitable.

Table 6. Average higher education expenditure in China from 2005 to 2011. Unit: Ten thousand yuan/student.

\begin{tabular}{|c|c|c|c|c|c|c|c|}
\hline Year & Nationwide & East & Central & West & Highest & Lowest & Highest/Lowest \\
\hline 2005 & 1.503 & 1.818 & 1.162 & 1.165 & $\begin{array}{l}\text { Tibet } \\
3.386\end{array}$ & $\begin{array}{l}\text { Ningxia } \\
0.751\end{array}$ & 4.50 \\
\hline 2006 & 1.533 & 1.840 & 1.177 & 1.224 & $\begin{array}{l}\text { Beijing } \\
3.415\end{array}$ & $\begin{array}{l}\text { Inner Mongolia } \\
0.853\end{array}$ & 4.00 \\
\hline 2007 & 1.632 & 1.948 & 1.231 & 1.307 & $\begin{array}{l}\text { Beijing } \\
3.466\end{array}$ & $\begin{array}{l}\text { Guizhou } \\
0.943\end{array}$ & 3.68 \\
\hline 2008 & 1.797 & 2.111 & 1.335 & 1.496 & $\begin{array}{l}\text { Beijing } \\
4.205\end{array}$ & $\begin{array}{l}\text { Henan } \\
1.011\end{array}$ & 4.16 \\
\hline 2009 & 1.865 & 2.125 & 1.409 & 1.644 & $\begin{array}{l}\text { Beijing } \\
4.170\end{array}$ & $\begin{array}{l}\text { Henan } \\
1.066\end{array}$ & 3.91 \\
\hline 2010 & 2.050 & 2.350 & 1.493 & 1.822 & $\begin{array}{l}\text { Beijing } \\
5.007\end{array}$ & $\begin{array}{l}\text { Henan } \\
1.138\end{array}$ & 4.40 \\
\hline 2011 & 2.475 & 2.744 & 1.837 & 2.264 & $\begin{array}{l}\text { Beijing } \\
6.581\end{array}$ & $\begin{array}{l}\text { Jiangxi } \\
1.312\end{array}$ & 5.01 \\
\hline
\end{tabular}

Source: YU Wei, ZHANG Peng (2015). Re-analysis on the Provincial Difference of Average Higher Education Expenditure in China: Based on the Decomposition of Shapley Value. China: Peking University Education Review. Vol. 13 No. 2, 2015 pp. 99-100.

2005-2011 the average higher education expenditure of 31 provinces and cities has increased every year, but due to the financial capacity, the investment mechanism of higher education, education market competition mechanism at the localities as well as educational investment orientations in localities are not the same make the average higher education expenditure between regions, between the localities very different. During seven years from 2005 to 2011, the average higher education expenditure in Beijing and Tibet is highest and the other provinces like Ningxia, Inner Mongolia, Guizhou, Henan, Jiangxi are still at lowest. In the period of 2005-2011, the highest and the lowest difference in average higher education expenditure among provinces and cities is expanded from 3.68 times to 5.01 times (see table 6).

The difference in higher education investment among provinces and cities makes training quality significantly impact on economic growth at the localities. Especially the provinces and cities with hot developing economy, wealth disparity, productivity gap, high difference in the level of scientific and technological progress between urban areas and rural areas and this requires local and national government to apply new and reasonably policies in adjusting investment funds of higher education in order to shorten the gap between investment in higher education between localities in the province as well as between the provinces and cities nationwide.

\subsection{Investment from Learners: Total Tuition Revenue Is Fast Growing, Tuition Standard Is Less Varied}

Total tuition revenue has been increased over the years, but variation in total tuition revenue of total investment funds tends to decrease.

Table 7. Total tuition revenue of Chinese higher education from 2005-2011. Unit: billion yuan.

\begin{tabular}{|c|c|c|c|c|}
\hline Year & 2005 & 2007 & 2009 & 2011 \\
\hline Number of students studying at universities (ten thousands of students) & 2300 & 2700 & 2979 & 3167 \\
\hline Total investment funds (A) & 265.79 & 376.23 & 478.28 & 702.09 \\
\hline Total tuition fees (B) & 83.79 & 127.74 & 159.39 & 186.23 \\
\hline $\mathrm{B} / \mathrm{A}(\%)$ & 31.52 & 33.95 & 33.32 & 26.52 \\
\hline
\end{tabular}

Source: National Bureau of Statistics of the People's Republic of China. The latest statistical data published on the website www.stats.gov.cn for total tuition revenue for higher education by 2011.

Total tuition revenue in 2011 reaches 186.23 billion yuan, an increase of 2.22 times compared to 2005. Total tuition revenue of total initial investment funds of a high percentage (over $30 \%$ of the total investment funds), then fell down to $26.52 \%$ in 2011 . In respect of standards of tuition fees. Variation in the standard tuition revenue of higher education is relatively slow. Specifically, in 2013 the standard academic year tuition revenue of universities under project 985 ranges from 4500 yuan to 5300 yuan, the universities of project 221 ranges from 3850 yuan to 6000 yuan. Total tuition revenue of the provincial universities ranges from 3500 yuan to 5000 yuan [1]. Compared to standard norms for average tuition revenue at universities in 2005 is 4968 yuan [2], it can be shown that the standard 
tuition revenue of universities is less varied in the period of 2005-2013.

Through analysis of the tuition problem, it shows that tuition revenue has grown rapidly over the years, but the standards of tuition revenue are slowly varied. This reflects an increase in tuition revenue mainly comes from scale of training. The government less adjusts higher education costs may create inequity issues in higher education investment, but it is the conditions and prerequisites for the families, especially the poor families to afford their children pursuing their study in universities thereby contributing to the target of massification and universalization of higher education.

\subsection{Limited Investment and Funding from Social Forces}

Investment funds of social forces for Chinese higher educationslowly grows and accounts for a limited ratio of total investment funds for higher education development in China. The highest is in 2005 , accounting for $1.15 \%$ of the total investment funds, the remaining years account for less than $1 \%$ of total investment funds. It shows that the benefits of investment in Chinese higher education development have not really attracted society to join in investment.

Table 8. Investment and financing of social forces from 2005 to 2011. Unit: billion yuan.

\begin{tabular}{lllll}
\hline Year & $\mathbf{2 0 0 5}$ & $\mathbf{2 0 0 7}$ & $\mathbf{2 0 0 9}$ & $\mathbf{2 0 1 1}$ \\
\hline Total investment funds (A) & 265.79 & 376.23 & 478.28 & 702.09 \\
Investment from social forces (B) & 3.08 & 3.19 & 3.31 & 3.33 \\
Sponsored by social forces (C) & 2.12 & 2.75 & 2.64 & 4.34 \\
B/A (\%) & 1.15 & 0.85 & 0.69 & 0.47 \\
C/A (\%) & 0.80 & 0.73 & 0.55 & 0.62 \\
\hline
\end{tabular}

Source: National Bureau of Statistics of the People's Republic of China. The latest statistical data published on the website www.stats.gov.cn for investment and funding of social forces for higher education by 2011.

Funding social force for higher education investment is also limited. 2005-2011, funding of social forces for the annual higher education accounts for less than $1 \%$ of the total investment funds. The highest is in 2011, total financing from the social forces in 2011 reaches 4.34 billion yuan, accounted for only $0.62 \%$ of total investment funds.

\section{Conclusions}

Via analysis of change characteristics with the correlation between GDP growth and growth in investment and development of Chinese higher education in the period of 2005-2013, we can draw some key following conclusions:

- Total investment funds of higher education have grown rapidly along with GDP growth. However, the growth rate of investment fundsis higher than scaling speed of training. That reflects investment funds of higher education development is still lacking compared to the need to expand the scale of training to aim at the objective of higher education universalizationin the future.

- The gap in per capita GDP and per capita income between provinces and cities, between urban areas and rural areas and between the economic areas reflects the economic development capacity is uneven across provinces and economic sectors. This directly impacts on average higher education expenditure between provinces and cities and between economic areas. Although the investment funds of the provinces and economic areas for students have increased over the years, but it is clearly imbalanced.

- Limited investment of social force for higher education shows that Chinese Higher Education has not really attracted individuals, organizations and businesses to join in investment.

- Price and solvency of students for higher education through tuition collection standards are relatively slow varied in the fast growth of per capita income which is the premise for the families to increase investment in higher education, step by step implementation of the higher education universalization plan.

- Through statistical analysis of total investment, investment rate from learners and social forces, it is shown that the investment budget from the state still plays a dominant role in the investment and higher education developmentin China with an annual rate of more than $50 \%$ of the total investment funds. Maintaining the key role of investment in higher education development in China will help Chinese government regulate macro investment in higher education development in accordance with the outlined objectives, strategies. However, economic growth tends to go down and not easy to forecast in the near future, and to implement strategic goals in the middle of the $21^{\text {st }}$ century, China will become a powerful country of higher education both in size and quality. China must also quickly enact reasonable and timely policies to raise additional investment capital outside the State budget. Especially from the social forces.

\section{References}

[1] Cao Shu-Jiang (2014). Some issues on tuition of Chinese Higher education. China: Journal of China higher education research Vol. 5, 2014 p. 47.

[2] HONG Liu (2013). Research on the Tuition Fees to the Influence of Chinese Higher Education Individual Investment. China: Journal of Higher Education Finance Vol. 16 No. 1, 2013 p. 3.

[3] Ministry of Education of the People's Republic of China. Statistical Report for Chinese Education Development by 2005-2013. Retrieved from www.moe.gov.cn

[4] National Bureau of Statistics of the People's Republic of China. GDP; per capita GDP and per capita income; CPI 2005-2013. Retrieved from www.stats.gov.cn

[5] National Bureau of Statistics of the People's Republic of China. Total investment funds for Higher Education 20052013. Retrieved from www.stats.gov.cn 
[6] National Bureau of Statistics of the People's Republic of China. Total tuition revenue, investment from social forces and funding of social forces for Higher Education 2005-2011. Retrieved from www.stats.gov.cn

[7] National Bureau of Statistics of the People's Republic of China. Rating per capita GDP of 31 provinces and cities in China in 2005 (not including Hong Kong, Macao and Taiwan). Retrieved from www.stats.gov.cn

[8] National Bureau of Statistics of the People's Republic of China. Rating per capita GDP of 31 provinces and cities in
China in 2013 (not including Hong Kong, Macao and Taiwan). Retrieved from www.stats.gov.cn

[9] YU Wei, ZHANG Peng (2015). Re-analysis on the Provincial Difference of Average Higher Education Expenditure in China: Based on the Decomposition of Shapley Value. China: Peking University Education Review. Vol. 13 No. 2, 2015 pp. 99-100.

[10] ZHAO Jingxiang (2015). Research on the relationship between Higher Education Investment and Economic Growth. China: Modern Economic Information. Vol. 10, 2015 p. 438. 